\title{
O ENSINO DA GINÁSTICA RÍTMICA: em busca de novas estratégias pedagógicas
}

\author{
Fernanda Raffi Menegaldo' \\ Marco Antonio Coelho Bortoleto?
}

\begin{abstract}
RESUMO
Este relato debate a experiência de uma ex-atleta, agora atuando como professora, no ensino da Ginástica Rítmica para crianças de cinco e seis anos de idade em um clube socioesportivo de Campinas-SP, cujo processo foi mediado por princípios pedagógicos utilizados comumente para a elaboração de composições coreográficas em grupos de Ginástica para Todos. A estratégia pedagógica relatada foi motivada, principalmente, devido ao desinteresse e à dispersão das alunas durante as aulas e pela consequente necessidade de mudanças. Dentre os resultados, destaca-se um aumento na participação e no envolvimento das ginastas, uma melhora no relacionamento entre elas e a professora e, ainda, um maior desenvolvimento quanto à autonomia e à capacidade de trabalho coletivo.
\end{abstract}

Palavras-chave: Esportes. Ginástica. Ensino.

1 Mestranda em Educação Física. Universidade Estadual de Campinas (UNICAMP). Campinas/ São Paulo, Brasil. E-mail: fernandamenegaldo@hotmail.com.

2 Doutor em Educação Física. Professor da Faculdade de Educação Física da Universidade Estadual de Campinas (FEF/UNICAMP). Campinas, São Paulo, Brasil. E-mail: bortoleto@fef.unicamp.br.

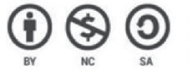

Este texto está publicado sob uma licença Creative Commons Atribuição NãoComercial-CompartilhaIgual - CC BY NC AS Mais detalhes em: https://br.creativecommons.org/licencas/ 
THE TEACHING OF RHYTHMIC GYMNASTICS: seeking new pedagogical strategies

\begin{abstract}
This article discusses the experience of an ex-athlete, who currently works as a teacher of Rhythmic Gymnastics with children between five and six years at a club in the city of Campinas. Her process of teaching will be modified through pedagogical principles based on the choreography composition of groups of Gymnastics for All. The pedagogical strategy reported was motived, mainly because of the disinterest and dispersion of the children during the class, and due to the need for changing. Between the obtained results a significant increase in participation and involvement of the gymnast's is highlighted, as well as an improvement in the relationship between them and the teacher. We also noticed a bigger development concerning to the autonomy and capacity for collective work.
\end{abstract}

Keywords: Sports. Gymnastics. Teaching.

\title{
LA ENSEÑANZA DE LA GIMNASIA RÍTMICA: en busca de nuevas estrategias pedagógicas
}

\section{RESUMEN}

Este relato debate la experiencia de una ex-atleta, actuando ahora como profesora, en la enseñanza de la Gimnasia Rítmica para niños de cinco y seis años de edad en un club socio-deportivo de Campinas-SP, cuyo proceso fue mediado por principios pedagógicos utilizados comúnmente para la elaboración de composiciones coreográficas en grupos de Gimnasia para Todos. La estrategia pedagógica relatada fue motivada, principalmente, debido al desinterés y dispersión de las alumnas durante las clases, y por su consecuente necesidad de cambios. Los resultados destacan un aumento en la participación y del desarrollo de las gimnastas y una mejora de la relación entre estas y la profesora. Notamos además un mayor desarrollo en relación a la autonomía y la capacidad de trabajo colectivo.

Palabras clave: Deportes. Gimnasia. Enseñanza. 


\section{INTRODUÇÃO}

Em todas as esferas da atividade humana, existem práticas que, embora frequentemente contestadas, resistem às mudanças. No que se refere ao ensino da ginástica, mais precisamente da Ginástica Rítmica (GR), mudanças na metodologia de ensino ainda representam um grande desafio, principalmente devido à consolidação de algumas práticas pedagógicas oriundas do treinamento de alto rendimento (SCHIAVON, 2003). A modificação das estratégias pedagógicas é ainda mais complicada, se a experiência se produz no interior de um clube socioesportivo tradicionalmente vinculado à prática esportiva de competição.

Considerando a problemática anteriormente apontada, este relato de experiência discute uma importante mudança pedagógica para o ensino da GR, a partir do desenvolvimento de alguns princípios de composição coreográfica comuns à ginástica não competitiva (Ginástica Geral ou Ginástica para Todos), com um grupo de crianças de cinco e seis anos de idade, em um clube socioesportivo privado da cidade de Campinas-SP, com longa tradição nessa modalidade esportiva (MENEGALDO, 2015; SARÔA, 2005).

A professora responsável pela referida experiência, coautora deste artigo, dedicou mais de uma década à sua carreira esportiva com a GR e, ao término dela, período que finalizava o curso superior em Educação Física (EF), teve a oportunidade de atuar como professora de um grupo de ginastas iniciantes. Foi precisamente nesse período de transição de atleta para professora que algumas das dificuldades pedagógicas se tornaram objeto de reflexão e posterior análise.

A possibilidade de ensinar GR para essa turma iniciante, composta por meninas, tornou-se um desafio desde o primeiro dia, principalmente porque os objetivos eram muito distintos daqueles vividos na condição de ginasta. O "novo" contexto em que essa experiência se desenvolvia não podia ser tão regrado, exigente e, por conseguinte, exclusivo, como aquele vivido durante os anos como ginasta de alto rendimento. E mais ainda, o início da experiência revelou um alto desinteresse das alunas, assim como uma grande dispersão durante as aulas.

Desse modo, ficou evidente que as estratégias pedagógicas adotadas para a turma iniciante não surtiam o efeito desejado. $\mathrm{O}$ modelo esportivo de alto rendimento que pautava a intervenção, e que, continuamente, buscava a perfeição, o rigor técnico e uma estratégia diretiva ou de "estilo de comando", nos termos cunhados por Mosston e Ahsworth (1972), precisava ser revisto e modificado. Em contraposição, o objetivo da prática em questão apontava para outra direção, ou seja, para a necessidade de oferecer uma vivência prazerosa, lúdica e inclusiva, similar ao proposto por Gaio (2009). Assim, a mudança no "paradigma" de ensino da GR foi desenvolvida a partir da proposta pedagógica do Grupo Ginástico Unicamp (GGU), coletivo, ao qual a professora teve a oportunidade de vincular-se e pelo qual pôde conhecer com maiores detalhes uma das formas possíveis para a prática da ginástica não competitiva, também denominada Ginástica Geral (GG), ou mais recentemente, Ginástica para Todos (GPT) (AYOUB, 2003, PAOLIELLO et al., 2014).

A construção deste relato de experiência fundamentou-se não apenas em memórias, lembranças, sentimentos, mas principalmente em registros sistemáticos (diários de aula), 
realizados pela docente durante o período da intervenção. Por ser a primeira experiência pedagógica externa ao contexto competitivo, a professora teve o cuidado de elaborar, a cada encontro, o plano de aula e registrar as "anotações de campo" (LANKSHEAR; KNOBEL, 2008), que permitiram, posteriormente, não apenas a análise do que tinha sido ou não bem-sucedido pedagogicamente, mas, em especial, o resgate de detalhes e situações importantes para o processo relatado a seguir.

Portanto, essa experiência aqui apresentada não esteve condicionada a priori à elaboração de um texto acadêmico-científico, e por conta disso, entende-se que a atuação da docente foi semelhante a uma observação participante natural (MARCONI; LAKATOS, 2003), no sentido de que a docente e observadora já pertencia ao grupo observado, tratando de estranhar sua própria ação no sentido de compreender o que estava acontecendo. Desse modo, a construção desse relato foi realizada após o término da experiência, motivada pelas transformações pedagógicas positivas vividas e percebidas pela professora.

\section{POR UMA PRÁTICA PEDAGÓGICA MAIS “FLEXÍVEL"}

Talvez eu esteja exagerando um pouco, mas o fato é que a falta de criatividade é um dos graves empecilhos para uma Educação Física de melhor qualidade. Tão grave quanto isso é realizar o exercício na forma como foi proposto. Quem só sabe seguir os manuais e as rotinas, será sempre escravo dos livros e dos ex-professores.

João Batista Freire

Embora a flexibilidade seja uma das capacidades físicas mais determinantes para o rendimento na GR e também para sua "identidade" como modalidade esportiva (LAFFRANCHI; LOURENÇO, 2006), foi no aspecto pedagógico que percebemos a necessidade de utilizar, mesmo que "simbolicamente", o conceito de flexibilidade.

Essa decisão se deu logo após as primeiras aulas, tempo suficiente para perceber que o modelo pedagógico aprendido durante os anos da carreira competitiva não poderia ser empregado naquele contexto. Embora tenha ficado claro, já no início, que a mudança era necessária, o processo foi inicialmente tenso e desgastante por conta da escassa experiência como docente e do "enraizado" referencial do treinamento competitivo. Mesmo cursando a Faculdade de Educação Física e tendo oportunidade de tomar conhecimento de outras concepções pedagógicas (PAES, 1996; PAES; BALBINO, 2009), a experiência no âmbito competitivo ainda era marcante.

Talvez a dificuldade encontrada não seja um problema particular, pois há muitos docentes da área da EF que possuem grande dificuldade de ensinar Ginástica de maneira distinta do modelo do treinamento de competição, como mostra o relato elaborado por Schiavon e Nista-Piccolo (2007) sobre uma experiência pedagógica com GR e GA, no contexto da extensão universitária. Segundo as autoras, esse fato limita a prática pedagógica da ginástica, o que pôde ser percebido rapidamente, e o que, em suas palavras, fica mais evidente: 
O desconhecimento sobre como aplicar a Ginástica, por parte dos professores, é a principal razão apresentada, mostrando que esses profissionais têm dificuldades em visualizar essa modalidade esportiva além da sua perspectiva competitiva. Isto é, eles não sabem quais são as contribuições da aprendizagem dessa modalidade para o desenvolvimento motor de seus alunos. Essa questão pode sugerir a existência de falhas na formação do profissional de Educação Física, relacionadas ao conhecimento da Ginástica como um fenômeno cultural que não se limita ao aspecto competitivo. (SCHIAVON; NISTA-PICCOLO, 2007, p. 132)

Nesse sentido, considerando a prática da Ginástica como uma vivência que pode ser realizada de maneiras distintas, Caçola (2007) discute a iniciação na GR, relatando que essa modalidade é composta por uma vasta diversidade de habilidades motoras severamente restringidas pela maioria dos professores, por encararem o processo de ensino-aprendizagem, desde os primeiros contatos das crianças com a modalidade, como uma reprodução dos padrões técnicos e procedimentais do treinamento de alto rendimento. Caçola (2007) e Schiavon e Nista-Piccolo (2007) ressaltam a necessidade de, por meio de uma concepção crítica, sensível, coletiva e inovadora, superar a concepção metodológica tradicional, cuja prática costuma ser rígida.

Apesar de existir o desejo de agradar a todas as crianças, buscando que todas retornassem aula após aula, as respostas das alunas indicavam certa insatisfação e, mais sutilmente, uma tendência à desmotivação. Em conversas com outras profissionais que ministravam aulas semelhantes no mesmo local, a professora já havia sido informada que o comprometimento das alunas das turmas de iniciação não competitiva (também denominadas "escolinhas") era muito distinto do observado com as ginastas que treinavam na equipe de competição, resultando essa diferença em uma flutuação no número de alunas participantes por conta da menor assiduidade e da baixa aderência.

No entanto, depois de algumas aulas, foi possível enxergar que, se as alunas estavam nas aulas, era porque, de alguma forma, gostavam de estar ali. Além disso, pôde-se observar que era responsabilidade da professora propiciar um espaço de boa convivência, lúdico e prazeroso, além da simples prática da GR. Foi, nesse momento, que ficou evidente que seriam necessárias mudanças. Era preciso buscar atividades criativas, desafiadoras e motivantes e que, mais que garantir a presença das alunas nos encontros seguintes, pudesse fortalecer o interesse pela ginástica, pelo grupo e por uma maior aproximação com a professora. Parece-nos que esse momento representou o que alguns teóricos denominam de "salto qualitativo", isto é, uma mudança na estratégia pedagógica: deixar de ministrar treinos para ministrar aulas de ginástica.

A principal referência adotada para essa mudança foi a proposta pedagógica desenvolvida pelo Grupo Ginástico Unicamp (GGU), com o qual a professora teve contato durante o curso de graduação. Sobre isso, Paoliello et al. (2014) relatam que a ginástica fomentada pelo GGU precisa ser vista como uma "prática para todos", sem fins competitivos, que integra distintas possibilidades e fundamentos da ginástica e oferece espaço para que diferentes formas de expressão corporal se manifestem de modo livre e criativo. Sob esses princípios, a proposta do GGU pretende alcançar o maior número possível de 
pessoas, estimular a interação social, facilitar a experiência de valores humanos como cooperação, respeito e amizade, não importando a faixa etária, o sexo, o nível técnico, ou mesmo a qualidade do repertório motor ou das capacidades físicas (PAOLIELLO, 1997).

Marcassa (2004) vê na proposta pedagógica do GGU uma possibilidade de inovação metodológica para as práticas gímnicas, pois modifica conceitos tradicionais como o de "retidão e verticalidade", típicos da vertente competitiva da ginástica e permite uma prática mais "flexível". A autora defende que a GG, ao mesmo tempo em que conserva a identidade da ginástica, simultaneamente, agrega valores e possibilidades. Em suas palavras:

Fundamentando-se nestes princípios, temos defendido a proposta da Ginástica Geral como aquela capaz de garantir a identidade da ginástica, mantendo seu conteúdo e forma, mas transcendendo aos aspectos meramente técnicos que predominam nas concepções mais tradicionais. Tal proposta amplia o universo dos exercícios e atividades ginásticas para uma compreensão de que o movimento gímnico é também expressivo, e de que a expressão é uma possibilidade, não só, de comunicação interna, referente ao conhecimento e à percepção que os sujeitos têm das suas próprias qualidades corporais, mas também de comunicação e contato entre as pessoas que partilham ou não do mesmo meio social ou de uma mesma sociedade e cultura (MARCASSA, 2004, p. 177).

Assim, pautando-se nessa concepção coletiva de ginástica, uma das primeiras ideias que a professora tentou estimular com o grupo de GR foi a da construção de uma unidade, de senso coletivo. No início, esse processo resultou em uma interação entre as crianças, diga-se de passagem, curiosa: formaram-se pequenos grupos, a maioria mantendo a relação existente no contexto extra-aula. Outros se formaram fortuitamente devido a afinidades pessoais. Gradualmente, a professora foi utilizando ferramentas que possibilitassem uma interação entre esses grupos. Sem ter a intenção de impor que as crianças estabelecessem uma relação de amizade, ela foi propondo atividades que instigassem a cooperação e o respeito.

Consideramos relevante salientar que, em alguns momentos, a professora pensou em desistir e regressar ao modelo pedagógico que dominava com maior competência, ou seja, impor regras, dividir grupos, conforme seus próprios critérios, e propor exercícios de acordo com as tradições do treinamento competitivo em GR. As dificuldades para elaborar aulas que promovessem o trabalho coletivo foram muitas, uma vez que se tratava de crianças pequenas e que não traziam incorporada essa experiência. Apesar disso, a professora decidiu insistir e apostar no tempo e na paciência.

Paulatinamente, esse "investimento pedagógico" começou a revelar seu potencial, tanto pessoal como profissionalmente. Perto de três meses depois do início das aulas, a professora notou que os encontros estavam mais "leves", alegres e acolhedores, e principalmente, que as alunas chegavam para as aulas cada vez mais animadas. Observou ainda uma mudança significativa no relacionamento entre elas que, a cada aula, interagiam mais entre si. Além disso, percebeu que, quanto mais elas construíam essas relações interpessoais, menor era o número das intervenções que ela precisava realizar durante as atividades. Foi 
possível, nesse momento, identificar a assimilação de uma atitude cada vez mais coletiva e autônoma nas alunas, bem distinta daquela do início das aulas.

Conforme reflexão embasada nos ensinamentos de Bortoleto (2004), aceitar um "novo" e mais amplo conceito sobre técnica, distinto daquele em que professora havia sido educada, foi um grande ganho, resultante dessa enriquecedora experiência. Durante anos, a professora foi sistematicamente orientada para atingir uma técnica "perfeita", devendo corrigir qualquer erro, mesmo aqueles quase imperceptíveis, buscar uma performance ótima. Esse conceito já não era mais possível de ser utilizado nessa nova proposta que estava sendo construída. Aliás, ele contradizia substancialmente os princípios que ela estava querendo desenvolver junto com o grupo mencionado.

De fato, conforme defende Bortoleto (2008), na ginástica não competitiva, relativiza-se o conceito tradicional da técnica, tratando, entre outros tópicos, de ampliar o repertório gestual para além do oferecido pelas modalidades de ginásticas competitivas, como a GA e a GR. Essa ampliação deve, portanto, pautar a ação pedagógica, tendo, como fundamentos referenciais, a criatividade e a segurança e não os regulamentos ou códigos gestuais típicos das modalidades competitivas. Por outro lado, a incorporação de aparelhos manipuláveis "alternativos" (distintos dos usados nas competições oficiais) também é uma forte característica da prática da ginástica não competitiva (GRANER, 2013), sendo essa também uma estratégia adotada pela professora no sentido de fomentar a criatividade a partir da exploração de movimentos para além daqueles comuns à GR.

De modo complementar, as aulas foram incorporando a elaboração de pequenas composições coreográficas coletivas, num primeiro momento orientadas e, pouco a pouco, realizadas de modo mais autônomo pelas crianças. Esse processo denominado "soma de frases" visa, essencialmente, oferecer um espaço criativo e de compartilhamento de saberes, por meio da apresentação das coreografias criadas para os demais companheiros, como explicam detalhadamente Paoliello et al. (2014). Assim, as aulas já não aconteciam pautadas fundamentalmente em exercitações individuais e na sucessiva repetição das habilidades típicas da GR.

Aos poucos foi se consolidando uma metodologia mais "flexível", que permitia adaptar e criar movimentos, ou mesmo incorporar outros provenientes de práticas diversas (gímnicas ou não). Para isso, a professora precisou minimizar, ou melhor, relativizar, seus julgamentos acerca da "técnica" das alunas. O "Código de Pontuação" da GR, decisivo na orientação do treinamento de alto rendimento, já não era "sagrado", embora não tivesse sido abandonado integralmente. Paralelamente a tudo isso, a professora procurou compreender as expectativas das crianças em relação às aulas e à própria prática da GR, tratando de oferecer práticas e dinâmicas variadas que despertassem maior interesse pelo esporte, pela GR e por suas aulas. Levou um considerável tempo para que a professora compreendesse que, tendo em vista a faixa etária de suas alunas, a abordagem pedagógica estaria mais próxima "do brincar de ginástica" ${ }^{3}$ do que de uma prática de "formação de atletas", pela

3 Entendemos o "brincar" como o eixo que orienta as práticas educativas para as crianças pequenas, como define Saul e Silva (2011), ao retomar as contribuições de Paulo Freire para a Educação Infantil. Dessa forma, para 
qual as crianças deveriam ser "preparadas" para se incorporarem às equipes de treinamento de GR do próprio clube. Logo, as aulas, então encontros lúdicos ${ }^{4}$, passaram a permitir que as alunas brincassem de fazer ginástica, o que, na visão da professora, foi fundamental para a melhoria da assiduidade, do interesse e da vontade em aprender mais e mais ginástica.

Ao deixar que o "brincar" conduzisse parte das aulas, a professora pôde notar o aparecimento de situações interessantes. Em alguns momentos, enquanto algumas alunas se mostravam extremamente habilidosas, outras demonstravam mais dificuldade para realização de alguns exercícios ou elementos corporais típicos da GR; em outros, nas brincadeiras ou no processo coreográfico criativo, por exemplo, esse quadro se invertia. Observar essa situação causou desconfortos para a professora, porque, embora interpretasse essas diferenças como um aspecto inerente à heterogeneidade do grupo, a sua escassa experiência em lidar com situações como essas Ihe trazia maior dificuldade para intervir e contribuir para a superação das dificuldades. Parece-nos que, aqui, a "herança" do modelo diretivo e a força da padronização de movimentos e técnicas da prática competitiva seguiam contribuindo para dificultar esse novo empreendimento pedagógico.

Entretanto, é válido ressaltar que o "brincar" também auxiliou a professora a perceber que as crianças que mostravam maior dificuldade eram mais expostas durante sua tentativa de utilizar o modelo "doutrinador" de ensino da GR, do que durante a prática mediada pelo brincar, pelo lúdico, pela criatividade e por uma prática coletiva. A proposta instalada favorecia nitidamente a atenuação das diferenças individuais e o fortalecimento da coesão do grupo.

Com paciência e, considerando as diferenças que permaneciam no grupo, priorizou o desenvolvimento de atividades nas quais as alunas exerciam papéis distintos ${ }^{5}$, mas sempre com o mesmo grau de importância. Buscou proporcionar às crianças o aprendizado de suas qualidades bem como as das colegas, a fim de harmonizar o grupo e, ao mesmo tempo, mostrar a diversidade de habilidades e possibilidades que tinham. Esse posicionamento

o caso da experiência relatada que trata de crianças de cinco e seis anos, em concordância com a pedagogia freiriana, consideramos que a brincadeira é uma condição para o aprendizado da criança, pois permite que ela aprenda "conceitos, valores, a expressar suas emoções e desenvolver seus sentidos orgânicos" (SAUL; SILVA, 2011, p. 6).

4 A expressão "encontros lúdicos" pode ser fundamentada pelo conceito de ludicidade de Santin (2001), que opõe o lúdico a rigidez da prática competitiva do alto rendimento em seu livro Educação Física: da alegria do lúdico a opressão do rendimento. Para o autor, a ludicidade está relacionada à humanidade e à essência do homem, e, entendendo o lúdico como o brincar, o autor reforça a necessidade de fomentar a ludicidade que seria a principal, e talvez única, maneira de a criança "relacionar-se consigo mesma, com os outros e o meio ambiente" (SANTIN, 2001, p. 30). Na perspectiva do autor, a racionalidade se contrapõe à ludicidade. Alega ele que o "homem da ciência e da técnica perdeu a felicidade e a alegria de viver, perdeu a capacidade de brincar, perdeu a fertilidade da fantasia, da imaginação guiadas pelo impulso lúdico" (SANTIN, 1994, p. 48). Nesse sentido, o presente relato perpassa o resgate desses valores atrelados à ludicidade, buscando fomentar uma conduta pedagógica que enalteça uma prática lúdica em detrimento de uma prática integralmente racional.

5 Quando utilizamos a expressão "papéis distintos", referimo-nos à prática menos padronizada, em que não é exigido que todas as alunas executem exatamente os mesmos movimentos simultaneamente, como ocorre em situações típicas da prática competitiva. Em uma situação de trabalho coletivo, por exemplo, esses "papéis" são atribuídos às alunas, não pela docente, mas, sim, pelas próprias crianças, que se organizam de acordo com suas habilidades e preferências individuais, contribuindo, assim, para a construção coletiva com o que cada uma julga possuir de qualidade. 
tem relação direta com os princípios da ginástica não competitiva, no qual cada pessoa é fundamental para o grupo, mesmo quando sua atuação se dilui, sem que se produza um ou mais "protagonistas". O produto final - a coreografia, por exemplo - é resultado do esforço e da colaboração de todos, da soma de suas qualidades em vista a uma "qualidade grupal" (PAOLIELLO et al., 2014).

No que diz respeito às diferenças entre as experiências individuais anteriores de cada aluna (com ginástica e também para além dela), Toledo e Schiavon (2008) ressaltam que o professor deve acionar uma estratégia metodológica que harmonize gradualmente as diferenças entre os participantes, sem que a prática e as coreografias produzidas percam a diversidade e, consequentemente, a contribuição dada por cada integrante do grupo à composição coreográfica. Desse modo, a prática da ginástica pode agregar diversidade de conceitos, culturas, movimentos e, principalmente, de significados para seus praticantes (PAOLIELLO, 2008).

Entre as atividades propostas, uma das mais atrativas e que mais nos chama a atenção, devido à sua importância para a criatividade e a identificação das alunas com a prática da GR, foi a "Soma de Frases" (PAOLIELLO et al., 2014), metodologia desenvolvida pelo GGU que se baseia na exploração de materiais e na criação de sequências coreográficas, de início de forma individual e posteriormente em grupos, somando aos poucos as sequências criadas, no intuito de construir uma passagem coreográfica. Ao final da dinâmica, é fundamental que os pequenos grupos apresentem suas criações entre si, a fim de socializar o que foi construído.

Além de se consolidar como uma das principais e mais desejadas dinâmicas realizadas em aula, a "Soma de Frases" estimulou não apenas a criatividade, mas também o entrosamento e, por conseguinte, a construção de uma visão coletiva de ginástica. Ajudou, ainda, na melhora da qualidade do convívio e no maior respeito entre as alunas. Todos esses benefícios informados têm relação, de acordo com Bondía (2002), com o processo experienciado e não com o produto, o que, em geral, acontece de forma inversa na prática competitiva, em que o produto final (resultados em competição) é o objetivo principal de treinadoras e ginastas.

Em constante diálogo com as crianças, a professora procurou utilizar músicas e temas que fossem familiares a elas, no intuito de deixá-las à vontade, de criar um ambiente familiar para explorar o material/tema proposto. Além de trabalhar com materiais alternativos - barangandã, bexigas, elástico, guarda-chuvas -, a professora não descartou o trabalho com os cinco aparelhos da GR - bola, corda, arco, maças e fita -, sem limitar esse trabalho aos fundamentos e aos exercícios típicos da modalidade. Embora tivesse utilizado durante a proposta os aparelhos oficiais, a intenção da professora era introduzir a lógica de exploração da GG no trabalho da GR, para que, dessa forma, o leque de movimentos manipulativos fosse cada vez mais amplo.

Com essa nova abordagem, foi possível notar um grande avanço do ponto de vista motor, bem como nos aspectos social, cognitivo e afetivo, o que tranquilizou a professora em relação ao objetivo proposto: ensinar a GR e também educar as crianças. A cada encontro, percebiam - a professora e as alunas - o quanto era prazeroso construir uma 
coreografia, a qual externasse o conteúdo que vinham desenvolvendo coletivamente ao longo das semanas. A professora procurou refletir, junto com as alunas, acerca de diferentes maneiras de elaborar a coreografia, optando por uma coreografia simples e que convidasse a todos os espectadores a compartilhar a coletividade, a cooperação, a interação, o respeito e o prazer presentes não apenas na coreografia, mas principalmente no processo de construção coreográfica.

Assim, em concordância com Sborquia (2008), o processo criativo, que tinha como finalidade alcançar uma intencionalidade e uma expressividade coletiva, foi como "uma fantasia" que se materializou à medida que foi partilhado com outras pessoas. Por conta da faixa etária das alunas, a montagem de uma coreografia de maior complexidade exigiria uma intervenção maior por parte da professora que, no entanto, esforçou-se, ao longo do processo de composição, para que a coreografia fosse uma criação das alunas. Isso possibilitou um maior envolvimento delas com esse processo criativo e potencializou o sentido de pertencimento ao grupo.

Para a explanação das opções temáticas, a professora organizou um encontro em que as alunas puderam assistir a trechos de diferentes filmes que continham músicas viáveis para a realização da coreografia. Subsidiada por tudo isso, ela promoveu uma discussão entre ela e as crianças em relação ao material e à música que seriam utilizados na coreografia final. Decidiram, coletivamente, utilizar o aparelho arco - material preferido pela grande maioria das alunas - e desenvolver a coreografia com a música "Hakuna Matata", tema dos personagens Timão e Pumba do filme Rei Leão. A partir dessas escolhas, a professora investiu em recursos que aproximassem a realidade das crianças ao contexto do filme escolhido, iniciando a montagem da coreografia de maneira gradual, fazendo referências contínuas ao cenário, aos personagens envolvidos e ao enredo da música.

Esse processo de criação, que também é pautado nos princípios da GG, é valorizado por outros autores que o utilizam como ferramenta pedagógica em suas aulas de Ginástica, como é o caso de Marcassa (2004), que, subsidiada por Ayoub (2003), define:

O processo de criação é a chave da ação pedagógica na medida em que se realiza a partir das referências anteriores que os indivíduos e grupos trazem para o contexto da aula, mas por meio de um envolvimento coletivo no trato do conteúdo e da forma coreográfica a ser alcançada. Esse processo é orientado pela tematização [...]. O momento da tematização deve ser norteado por uma pesquisa ou investigação que permita aos alunos aprofundar os saberes que já possuem sobre determinada questão para além das informações que trazem consigo, das imagens primeiras, ou dos dados que estão disponíveis no plano das aparências (MARCASSA, 2004, p. 179).

Em sua dissertação de mestrado, Graner (2013), ao relatar sua experiência de ensino da GG na escola, também adota como referência Ayoub (2003), afirmando que o ensino da ginástica pode ser consolidado por meio de um "confronto" entre as formas tradicionais e inovadoras de exercitação, o que possibilita aos alunos a atribuição de um sentido próprio às suas práticas gímnicas. Essa atribuição de sentido, de significado à prática da ginástica, ligada fundamentalmente às teorias críticas do ensino da EF, era, sem dúvida, um dos objetivos da professora ao transformar sua metodologia. 
Nista-Piccolo (1995), também citada por Graner (2013), propõe um modelo de ensino pautado em três momentos: o professor coloca os alunos em contato com a temática da aula, sem ainda descrever qual gesto deve ser executado, incentivando-os a explorar possíveis alternativas de movimentos; posteriormente, são oferecidas apenas algumas pistas sobre o movimento que se deseja realizar, sem limitar os alunos a um padrão gestual; e, por fim, apresentam-se os gestos que não foram explorados pelos alunos. Esse processo, também utilizado por Schiavon (2003), é, em linhas gerais, o modelo que a professora em questão tentou adotar ao longo de suas aulas e durante o processo de montagem coreográfica, sempre se atentando para o que as alunas criavam e para o significado dessas criações, intervindo, ao fim, apenas com o objetivo de complementar e enriquecer as aulas e a coreografia, lapidando-a para a apresentação e visando a uma questão de estética coreográfica, sem que ela perdesse o significado para as crianças.

Construíram, assim, uma coreografia não muito extensa, com movimentos gímnicos básicos e com formações coreográficas amplas que facilitassem a visão entre as alunas. Simultaneamente, a professora arriscou colocar elementos coletivos, também semelhantes a movimentos construídos pelas alunas nas "Soma de Frases", que, no fim do processo, foram os elementos que esteticamente mais impactaram e deram grande visibilidade à coreografia.

Sabendo que a apresentação no festival seria seu último contato com as alunas devido à sua saída da instituição, a docente viveu momentos de ansiedade paralelos ao desejo de que cada aula fosse especial e construtiva, no sentido de poder contribuir expressivamente para o desenvolvimento e para a formação humana das alunas. Chegado o dia do festival, ela se sentiu com a sensação de dever cumprido, não só por presenciar o sucesso da coreografia, mas também por observar o quanto aquela prática tinha ganhado um significado para a turma, e o quanto as alunas se sentiram especiais durante a apresentação.

Ao final desse ciclo, após a apresentação de sua turma no festival, a sensação da professora, ao ver o resultado do seu trabalho em conjunto com as crianças, foi indescritível. Ela tinha tido e vivido muitas situações no universo da GR competitiva, mas em nenhuma delas se lembra de ter se sentido tão competente e realizada. Obviamente, os resultados da ginástica competitiva e da ginástica demonstrativa são extremamente diversos e, por conta disso, dificilmente se pode comparar a satisfação de bons resultados nas duas práticas. Porém, poder contribuir para a formação humana das alunas e sentir a receptividade dessa proposta por parte das crianças consolidou gratificante e diferente de qualquer outra experiência possibilitada anteriormente pelo universo da ginástica.

\section{CONSIDERAÇÕES FINAIS}

Se, de acordo com Fiorin-Fuglsang e Paoliello (2008), a GG pode ser considerada como uma possibilidade de um fazer gímnico contextualizado, isto é, onde o participante tem a oportunidade de aprender ginástica ao passo que interage com outros elementos da cultura corporal, criando ou recriando de modo participativo, parece-nos que é possível pensar o ensino da GR, ao menos em seus momentos iniciais, a partir desses mesmos 
princípios. Em outras palavras, é possível pensar e aplicar uma metodologia mais flexível, coletiva, menos especializada, visando a um contato significativo e prazeroso com a modalidade.

Refletindo de maneira mais ampla, ou seja, para além da prática gímnica, acreditamos que a experiência aqui narrada retrata uma dificuldade enfrentada por muitos professores de EF no contexto educativo. A proposta de intervenção da professora é reflexo da sua percepção de que o distanciamento entre docente e discente, resultado de um modelo pedagógico tradicional - centralizado, composto apenas por uma só voz - não conseguia despertar o interesse das suas alunas e motivá-las em suas aulas. A necessidade de mudança da docente se fortalece, portanto, no momento em que ela compreende que, quanto mais "porosa" e descentralizada fosse sua atuação como professora, maior seria a participação e a construção de autonomia por parte de suas alunas.

Considerando essa proposta, ficou evidente, ao longo da narrativa dessa experiência, que o trabalho realizado com esse grupo de crianças foi igualmente rico do ponto de vista técnico e, em nossa opinião, mais efetivo nos aspectos educativo, formativo e lúdico, como sugere Ayoub (2003). Tudo isso sem que houvesse a necessidade de impor e direcionar as crianças constantemente ou, em outras palavras, de "doutriná-las".

\section{REFERÊNCIAS}

AYOUB, Eliana. Ginástica geral e Educação Física escolar. Campinas: Unicamp, 2003. BONDÍA, Jorge Larrosa. Notas sobre a experiência e o saber de experiência. Revista Brasileira de Educação, n. 19, 2002.

BORTOLETO, Marco Antonio Coelho. La lógica interna de la Gimnasia Artística Masculina y estudio etnográfico de un Gimnasio de alto rendimento. (Doutorado em La investigación en la actividad física y deporte) - Universidade de Lleida, Espanha, 2004. BORTOLETO, Marco Antonio Coelho. Uma reflexão sobre o conceito de técnica na Ginástica Geral. In: PAOLIELLO, Elizabeth. Ginástica Geral: experiências e reflexões. São Paulo: Phorte, 2008. p. 167-190.

CAÇOLA, Priscila. A iniciação esportiva na Ginástica Rítmica. Revista Brasileira de Educação Física, Esporte, Lazer e Dança, v. 2, n. 1, p. 9-15, mar. 2007.

FIORIN-FUGLSANG, Cristiane Montozo; PAOLIELLO, Elizabeth. Possíveis relações entre a Ginástica Geral e o Lazer. In: PAOLIELLO, Elizabeth. Ginástica Geral: experiências e reflexões. São Paulo: Phorte, 2008. p. 97-120.

GAIO, Roberta. Ginástica Rítmica Popular: uma proposta educacional. 2. ed. Jundiaí: Fontoura, 2009. v. 1. 152p.

GRANER, Larissa Silva Pinto. O processo de ensino-aprendizagem da ginástica na "minha escola". Dissertação (Mestrado) - Universidade Estadual de Campinas, Faculdade de Educação. Campinas, 2013.

AFFRANCHI, Barbara Elisabeth; LOURENÇO, Márcia Regina Aversani. Ginástica Rítmica - da iniciação ao treinamento de alto nível. In: GAIO, Roberta; BATISTA, José Carlos de Freitas. A ginástica em questão. Ribeirão Preto: Tecmedd, 2006. 
LANKSHEAR, Colin; KNOBEL, Michele. Pesquisa pedagógica: do projeto à implementação. Porto Alegre: Artmed, 2008.

MARCASSA, Luciana. Metodologia de Ensino da Ginástica: novos olhares, novas perspectivas. Pensar a Prática, v.7, n.2, p. 171-186, jul./dez. 2004.

MARCONI, Maria de Andrade; LAKATOS, Eva Maria. Fundamentos de metodologia científica. 5. ed. São Paulo: Atlas, 2003.

MENEGALDO, Fernanda Raffi. A parceria público-privada como alternativa para sustentabilidade de uma equipe de Ginástica Rítmica da cidade de Campinas-SP. (Monografia) Universidade Estadual de Campinas, 2015.

MOSSTON, Muska; AHSWORTH, Sara. Teaching: from command to discovery. Belmont: Wadsworth Publication Co. 1972.

NISTA-PICCOLO, Vilma Leni. A educação motora na escola: uma proposta metodológica à luz da experiência vivida. In: DE MARCO, Ademir. (Org.). Pensando a educação motora. Campinas: Papirus, 1995.

PAES, Roberto Rodrigues. Educação Física Escolar: o esporte como conteúdo pedagógico no Ensino Fundamental. Tese (Doutorado em Educação Física). Faculdade de Educação Física, Universidade Estadual de Campinas, Campinas, 1996.

PAES, Roberto Rodrigues; BALBINO, Hermes Ferreira. A pedagogia do esporte e os jogos coletivos. Cap.5, p. 73-83. In: DE ROSE JUNIOR, Dante. et al. Esporte na infância e adolescência: uma abordagem multidisciplinar. 2. ed. Porto Alegre: Artmed. 2009.

PAOLIELLO, Elizabeth. Ginástica Geral: uma área do conhecimento da Educação Física. Tese (Doutorado) - Universidade Estadual de Campinas, Campinas, 1997.

PAOLIELLO, Elizabeth. Nos Bastidores da Ginástica Geral: o significado da prática. In: PAOLIELLO, Elizabeth. Ginástica Geral: experiências e reflexões. São Paulo: Phorte, 2008. p. 191-216.

PAOLIELLO, Elizabeth; TOLEDO, Eliana; AYOUB, Eliana; BORTOLETO, Marco Antonio Coelho; GRANER, Larissa Silva Pinto. Grupo Ginástico Unicamp: 25 anos. Campinas: Unicamp, 2014.

SANTIN, Silvino. Educação Física: da alegria do lúdico à opressão do rendimento. 3. ed. Porto Alegre: EST Edições, 2001.

SARÔA, Giovana. A história da Ginástica Rítmica em Campinas. Dissertação (Mestrado em Educação Física) - Universidade Estadual de Campinas, Campinas, 2005.

SAUL, Alexandre; SILVA, Camila Godói da. Contribuições de Paulo Freire para a educação infantil: implicações para as políticas públicas. In: Simpósio Brasileiro de Política e Administração da Educação, São Paulo, 2011.

SBORQUIA, Silvia Pavesi. Construção coreográfica: o processo criativo e o saber estético. In: PAOLIELLO, Elizabeth. Ginástica Geral: experiências e reflexões. São Paulo: Phorte, 2008. p. 145-166.

SCHIAVON, Laurita. O projeto crescendo com a Ginástica: uma possibilidade na escola. (Mestrado em Educação Física) - Universidade Estadual de Campinas, Campinas, 2003. SCHIAVON, Laurita; NISTA-PICCOLO, Vilma Leni. A Ginástica vai à escola. Movimento, Porto Alegre, v. 13, n. 03, p. 131-150, set./dez. 2007. 
TOLEDO, Eliana; SCHIAVON, Laurita. Ginástica Geral: diversidade e identidade. In:

PAOLIELLO, Elizabeth. Ginástica Geral: experiências e reflexões. São Paulo: Phorte, 2008. p. 217-238.

Recebido em: julho/2016

Aprovado em: dezembro/2016 